\title{
Uterine Perforation after Pose of IUD, the Place of Abdomen Radiography without Preparation
}

\author{
Abdel Karim Sermé1, Aboubacar Coulibaly ${ }^{1}$, Koumpielimé Sosthène Somda1, \\ Dimitri Darankoum1, Delphine Napon/Zongo², Soré Moussa Zanga3, \\ Hector Godonou' ${ }^{1}$, Kadidiatou Cissé ${ }^{1}$, Issiaka Ouedraogo ${ }^{1}$, Ali Ouedraogo ${ }^{4}$ \\ ${ }^{1}$ Gastroenterology Service of the University Hospital Centre Yalgado Ouédraogo (CHUYO), Ouagadougou, Burkina Faso \\ ${ }^{2}$ Gastroenterology Service of the University Hospital Centre Sanou Sourou (CHUSS), Bobo Dioulasso, Burkina Faso \\ ${ }^{3}$ Medical Imaging Department of the Charles de Gaulle Pediatric University Hospital Center (CHUP-CDG), \\ Ouagadougou, Burkina Faso \\ ${ }^{4}$ Gyneco-Obstetrics Service of the University Hospital Centre Yalgado Ouédraogo (CHUYO), Ouagadougou, Burkina Faso \\ Email: coulibacar@yahoo.fr
}

How to cite this paper: Sermé, A.K., Coulibaly, A., Somda, K.S., Darankoum, D., Napon/Zongo, D., Zanga, S.M., Godonou, H., Cissé, K., Ouedraogo, I. and Ouedraogo, A. (2017) Uterine Perforation after Pose of IUD, the Place of Abdomen Radiography without Preparation. Open Journal of Gastroenterology, 7, 1-4.

http://dx.doi.org/10.4236/ojgas.2017.71001

Received: December 7, 2016

Accepted: January 3, 2017

Published: January 6, 2017

Copyright () 2017 by authors and Scientific Research Publishing Inc. This work is licensed under the Creative Commons Attribution International License (CC BY 4.0).

http://creativecommons.org/licenses/by/4.0/

\begin{abstract}
Uterine perforation is a serious complication after insertion of an intrauterine device (IUD). We report the case of a 34-year-old woman receiving in consultation for abdominal pain. In the interrogation there was a notion of IUD insertion for about a week. The gynecological examination did not find the thread of IUD and the ultrasound performed did not visualize an IUD. Radiography of the abdomen without preparation highlighted a compatible intrapelvic foreign thing like an IUD. The diagnosis of pelvic inflammatory disease by uterine perforation by an IUD was thus retained. We suggest in case of suspicion of uterine radio paque IUD perforation achieving radiography when the abdominal pelvic ultrasound is normal.
\end{abstract}

\section{Keywords}

IUD, Intra, Uterine Perforation, Diagnosis, Treatment

\section{Introduction}

The intrauterine device (IUD) is an effective contraceptive method with long duration action used in our country as part of family planning [1]. However, its installation can sometimes be a source of major complications such as uterine perforation. This is a rare and serious complication which can cause a diagnostic problem in our context where the technical equipment is often lacking. In this article, we propose to illustrate through observing the place of abdomen radio- 
graphy without preparation in the diagnosis of uterine perforation by an IUD.

\section{Observation}

Mrs T/G N, 34, secretary-accountant, living in Ouagadougou, was 4th and 2nd parity gesture (2 living children, 1 caused abortion and 1 miscarriage). An intrauterine device (DIU) had been set up in a therapeutic purpose. One week after this act appeared abdominal pains. The gynecological examination did not find the thread of IUD. Pelvic ultrasound performed thereafter did not highlight the DIU in the pelvis. It was concluded then a spontaneous loss of the IUD. The patient was referred to gastroenterology consultation February 19, 2014, one week later. Pelvic pains belonged to type of twisting activated by food intake, relieved by vomiting and associated with a low grade fever especially Vespers at $38^{\circ} \mathrm{C}$ and asthenia.

Clinical examination was poor with a fairly good health, non-icteric colored conjunctiva.

The abdomen was without spasm but with significant defense in the pelvic region.

Paraclinic exploration highlighted an inflammatory anemia without leukocytosis in the blood count, with an accelerated erythrocyte sedimentation rate 80 $\mathrm{mm}$ in the first hour. The abdominal-pelvic ultrasound found a minimal peritoneal effusion. The high and low endoscopies were normal. An endovaginale ultrasound realized was also without particularity. Tests of HIV 1 and 2, B and C virus hepatitis were negative. Hepatic and cardiac assessments were also without particularities.

Radiography of the abdomen without preparation (ASP) showed a foreign body intra-pelvic seems like an IUD (Figure 1).

The diagnosis of pelvic inflammatory disease by uterine perforation by an

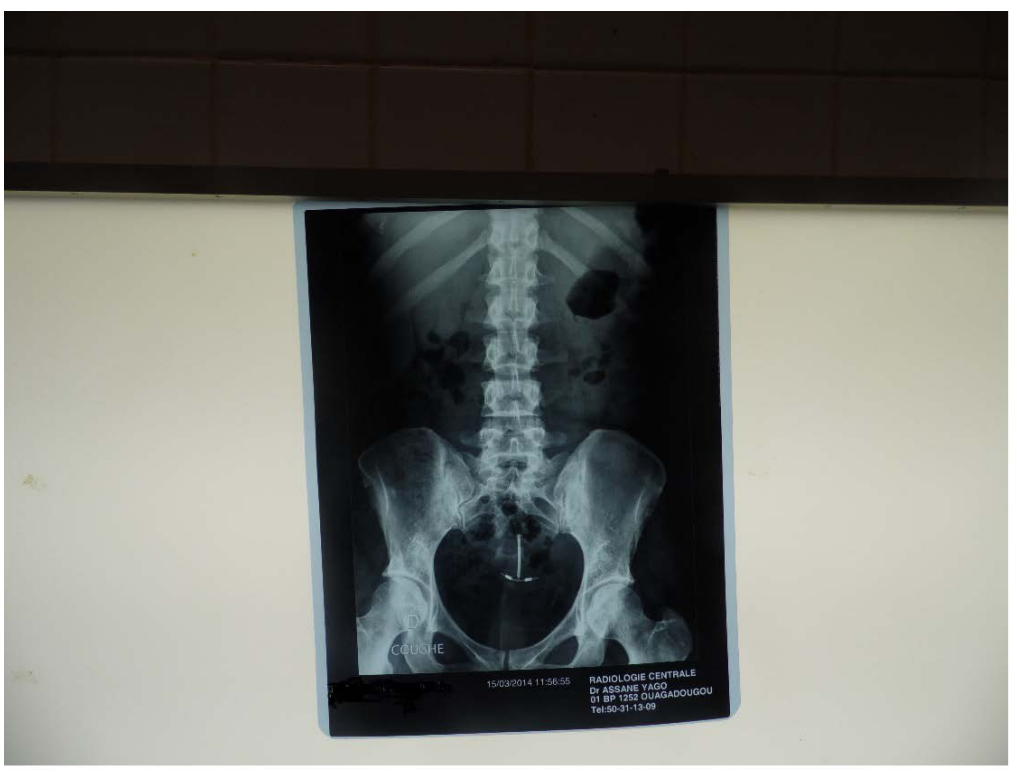

Figure 1. Radiography of the abdomen without preparation (ASP) showed a foreign body intra-pelvic seems like an IUD. 
IUD was retained. Surgery confirmed the diagnosis. The postoperative sequences were simple.

\section{Discussion}

The uterine perforation by IUD is easily evoked during the appearance or the accentuation of pelvic pain after the pose of IUD and when we cannot find the threads during a gynecological check. This was the case of our patient. The IUD, or intrauterine device (IUD) is a means of reversible contraception and widely used. Its insertion constitutes an invasive procedure and not deprived of complications such as pains, bleedings, infections, spontaneous expulsions, perforations and even pregnancies. This perforation is related to various factors such as: operator inexperience, the introduction strength and uterine causes (weakening of the myometrium by multiple pregnancies and cesarean). Our patient, 4th gesture enjoyed that contraception after an abortion. Uterine perforation is the most serious complication occurring during the insertion. The frequency of this complication ranges from 0.05 to 13 for 1000 insertions of the DIU, that is on average 1.2 for 1000 [2] [3] [4]. Uterine perforation can be partial or complete with the IUD in the abdominal cavity. Perforation is suspected in front of especially pelvic pains and the disappearance of threads of the IUD during gynecological examination, such as find in our patient's

The imaging is a great benefit in the topographical diagnosis of the migrated IUD.

The abdominopelvic ultrasound is then indicated in the first intention [5] [6]. It shows a uterine cavity without IUD or an IUD in para-uterine. Sometimes it didn't find IUD but cannot assert the uterine perforation. The endovaginale ultrasound is a better yield to appreciate the uterine vacuity. In our patient, it was performed twice and was not contributory. This examination did not find the IUD in extra uterine. If the IUD is not observed through echotomy, we shall refer to the recommendations that prescribed a computed tomography (CT) or Magnetic resonance imaging (MRI). The radiography of the abdomen without preparation lost its place in this indication in front of these new imaging techniques. The radiography of the abdomen without preparation realized at our patient after exploration of the other diagnostic hypotheses allowed to highlight a pelvic foreign body which was other than the DIU. Indeed all the IUD is radioopaque and can be highlighted to the standard radiography of the abdomen without preparation. Seen the reduced accessibility of the new imaging techniques in our context and the radio-opacity of the IUD, we think that it is necessary to give to the ASP the place of examination of second intention [7] [8] [9] [10]. In addition, providers should insist on post-insertion control and signs of danger requiring consultation before IUD insertion

The treatment of uterine perforation after IUD insertion will be to his removal under hysteroscopy if incomplete perforation or laparoscopic/laparotomy for complete perforation associated with primary closure and/or resection [11] [12]. 


\section{Conclusion}

The ASP should be the second examination to be carried out in the regions in case of suspicion of uterine perforation by a radiopaque IUD with normal abdominopelvic ultrasound.

\section{References}

[1] Markovitch, O., Klein, Z., Gidoni, Y., Holzinger, M. and Beyth, Y. (2002) Extrauterine Mislocated IUD: Is Surgical Removal Mandatory? Contraception, 66, $105-$ 108. https://doi.org/10.1016/S0010-7824(02)00327-X

[2] Guiella, G. (2015) Indicateursclés de planification familiale PMA/Burkina FasoVague 2. www.pma2020.org

[3] Zouhal, A., Amrani, N., Bensaid, F., et al. (2000-2001) Migration intra-vésicale d'un dispositif intra-utérin: à propos d'un cas. Mater Univ Orang.

[4] Ech-Chérif El Kettani, N. and Dafiri, R. (2007) Imagerie de la migration des dispositifs intra-utérins. Feuillets de Radiologie, 47, 159-166. https://doi.org/10.1016/s0181-9801(07)88852-x

[5] Khaled, B., Marouane, B.A., Lofti, B.H., et al. (2001) Dispositif intra-utérin migré dans la vessie. Progrès en Urologie, 11, 1289-1291.

[6] Ledward, R.S., Healey, C. and Eadie, R. (1972) Removal of Extra-Uterine Saf-T-Coil through Laparoscope. British Medical Journal, 1, 508. https://doi.org/10.1136/bmj.1.5798.508-a

[7] Brar, R., Doddi, S., Ramasamy, A. and Sinha, P. (2010) A Forgotten Migrated Intrauterine Contraceptive Device Is Not Always Innocent: A Case Report. Case Reports in Medicine, 2010, Article ID: 740642.

[8] Zakin, D., Stern, W.Z. and Rosenblatt, R. (1981) Complete and Partial Uterine Perforation and Embedding Following Insertion of Intrauterine Devices: Classification, Complications, Mechanism, Incidence, and Missing String. Obstetrical \& Gynecological Survey, 36, 335-353.

[9] Wail, B., Fatime, Z.F.A., Sofia, J., Hakima, B. and Moulay, A.M. (2014) Migration intra-péritonéale d'un dispositif intra-utérin diagnostiqué 20 ans après l'insertion: à propos d'un cas. The Pan African Medical Journal, 17, 7.

[10] Pont, M. and Lantheaume, S. (2009) Abdominal Migration of a Levonorgestrel Releasing Intrauterine Device: Case Report and Review of the Literature. Journal de Gynécologie Obstétrique et Biologie de la Reproduction, 38, 179-181. https://doi.org/10.1016/j.jgyn.2009.01.005

[11] Treiman, K., Laurie, L.S.C.M., Adrienne, K., et al. (1995) Les DIU: état récent des informations. Population Reports Journal, 6, 1-35.

[12] Gruber, A., Rabinerson, D., Kaplan, B., Pardo, J. and Neri, A. (1996) The Missing Forgotten Intrauterine Contraception Device. Contraception, 54, 117-119.

https://doi.org/10.1016/0010-7824(96)00135-7 
Submit or recommend next manuscript to SCIRP and we will provide best service for you:

Accepting pre-submission inquiries through Email, Facebook, LinkedIn, Twitter, etc. A wide selection of journals (inclusive of 9 subjects, more than 200 journals)

Providing 24-hour high-quality service

User-friendly online submission system

Fair and swift peer-review system

Efficient typesetting and proofreading procedure

Display of the result of downloads and visits, as well as the number of cited articles Maximum dissemination of your research work

Submit your manuscript at: http://papersubmission.scirp.org/

Or contact ojgas@scirp.org 